\title{
Monitoramento da precipitação e vazão em uma microbacia com plantio de Eucalipto no município de Francisco Dumont, MG
}

\author{
Vanessa Pataro Maffia ${ }^{1}$ \\ Herly Carlos Teixeira Dias ${ }^{1}$ \\ Otávio Surian Gambás² \\ Ana Paula Vilela Carvalho \\ ${ }^{12}$ Universidade Federal de Viçosa - UFV \\ Avenida Peter Henry Rolfs, s/n, Campus Universitário - 36570-000 -Viçosa - MG, Brasil \\ vpmaffia@yahoo.com.br \\ herly@ufv.br \\ otaviosurian@hotmail.com \\ aninhafloresta@hotmail.com
}

\begin{abstract}
Monitoring water flow is important to quantify the readiness of water in watersheds; it is also able to relate the flow variation with environmental effects during different seasons of year. This monitoring also can relate responses from different soil uses which are fundamental importance to develop actions to minimize environmental impacts. The main objective of this work was to quantify the variation of the stream flow named Águida, in Espírito Santo Farm, located at Francisco Dumont, MG, Brazil. This farm is property of Scflor Agricultural Enterprises and is occupied by eucalyptus plantation since 2007, when started the monitoring. The monthly flows were measured as much as all of the rain events. The annual precipitation can be divided in two defined periods, a summer period, September to March, $862,4 \mathrm{~mm}$ of rain and the dry period, April to August, $14,1 \mathrm{~mm}$ of rain. After the data is crossed, a great variation of the flow was observed among the months of larger and smaller precipitation.
\end{abstract}

Palavras-chave: Bacia hidrográfica, monitoramento hidrológico, precipitação, vazão, reflorestamento.

\section{Introdução}

A água é um recurso vital para a vida na Terra que embora renovável é finito, e ao longo das últimas décadas sua qualidade vem sendo rapidamente deteriorada. A qualidade e a quantidade de água são afetadas por uma série de fatores externos, tanto naturais quanto antrópicos, os quais incluem a hidrografia, o clima, a geologia, os usos do solo, a alteração da cobertura vegetal, entre outros.

O uso e ocupação do solo sem considerar suas características de hidrografia, clima, geologia, cobertura vegetal, podem contribuir para degradação do ambiente. As conseqüências mais comuns observadas são a eutrofização, os assoreamentos, as alterações no volume de água dos rios, a contaminação por poluentes e a piora da qualidade da água.

O monitoramento da vazão de um curso de água é importante para quantificar o volume de água em uma determinada bacia. Desta forma as diversas atividades desenvolvidas em bacias hidrográficas com alteração do uso e ocupação do solo interferem diretamente no regime temporal e espacial da vazão e na qualidade da água. Seu monitoramento, neste sentido, pode então fornecer informações importantes sobre o equilíbrio da bacia.

Outra característica importante da microbacia reside no fato de que, mesmo sendo um sistema aberto e limites bem definidos, o equilíbrio varia constantemente. Sua dinâmica é observada através de uma contínua condição transiente. Desta forma, seu funcionamento hidrológico é complexo e bastante estável, no sentido de suportar adequadamente perturbações naturais quando em boas condições de cobertura florestal. Por essa mesma razão, a microbacia é, também, altamente vulnerável a perturbações, cujas alterações se refletem na qualidade e quantidade da água (Perry \& Maghembe, 1989). 
O uso de microbacias hidrográficas como unidade experimental iniciou por volta do começo deste século em vários países, e os inúmeros resultados obtidos mostram, cabalmente, que o uso da terra e as atividades antrópicas afetam a quantidade e o regime da vazão, bem como a qualidade da água. Muito mais importante, todavia, são as evidências demonstradas em vários trabalhos experimentais de que é perfeitamente possível, com base no conhecimento da dinâmica da microbacia, realizar operações de produção florestal com um mínimo de impacto à qualidade da água (Aubertin \& Patric, 1974).

Desta forma, este trabalho teve por objetivo quantificar a variação da vazão do córrego Águida, no município de Francisco Dumont, relacionando a precipitação de chuvas com o crescimento do eucalipto, em diferentes épocas do ano. Este monitoramento é importante para quantificar a disponibilidade de água na microbacia como também relacionar a variação da vazão de diferentes épocas do ano aos efeitos ambientais e antrópicos.

\section{Materiais e métodos}

\subsection{Descrição da área}

A microbacia experimental monitorada localiza-se no município de Francisco Dumont, microregião de Bocaiúva na região Centro-Norte do Estado de Minas Gerais, nas coordenadas $17^{\circ} 18^{\prime} 54^{\prime \prime S}$ e $44^{\circ} 14^{\prime} 02^{\prime \prime O}$ (Figura 1). O trabalho esta sendo realizado na Fazenda Espírito Santo de propriedade da empresa Scflor Empreendimentos Agrícolas Ltda., que vem promovendo o reflorestamento com Eucalipto na região. A microbacia do Córrego Águida, na Serra do Cabral. O córrego Águida deságua no Rio Jequitaí, que por sua vez deságua na margem direita do Rio São Francisco, que forma uma das mais importantes bacias hidrográficas do Brasil. (Figura 2).

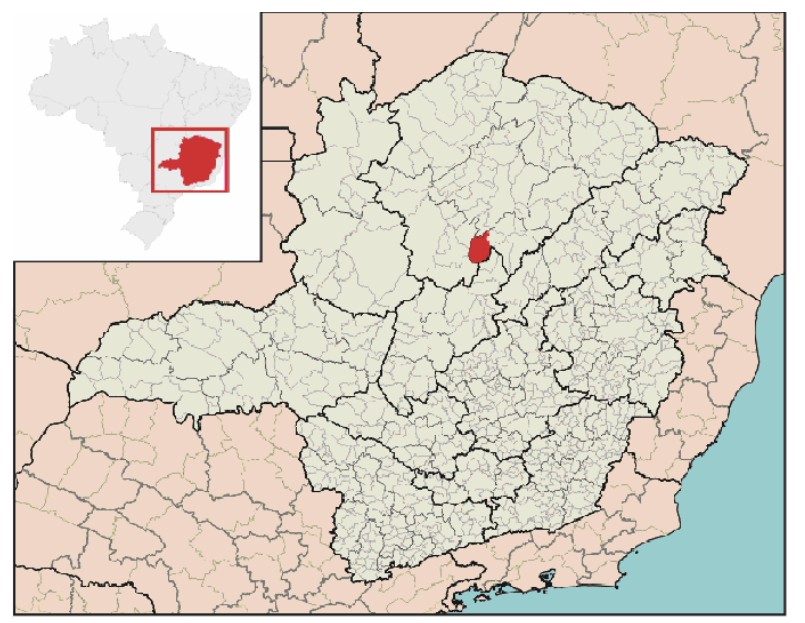

Figura 1: Cidade de Francisco Dumont, Centro-norte de estado de Minas Gerais

O clima predominante na região segundo a classificação de Köppen é do tipo tropical de altitude, com verões quentes e chuvosos e invernos secos (Cwa).

O histórico do uso do solo da Serra do Cabral apresenta um cenário com áreas degradadas e abandonadas após a exploração dos plantios de pinus executados com recursos do incentivo fiscal na década de 80. A legislação da época e as técnicas de plantio contribuíram para da área. A partir de 2007, ano que a empresa SCFLOR adquiriu áreas na região foram realizados reformas das áreas com Eucalipto, delimitação das áreas de APP's, inativação de estradas, 
recuperação da área retirando os fornos de carvão irregulares (que se encontravam próximos as nascentes e dentro das veredas), e iniciou-se o monitoramento hidrológico da bacia.

A Serra do Cabral possui um grande potencial para o turismo ecológico e o município de Francisco Dumont se destaca neste contexto pela flora e fauna muito rica, inúmeras quedas de água e uma piscina natural no centro da cidade que é grande atração da população regional. Desta forma, o monitoramento das vazões dos cursos de água que drenam as piscinas naturais sob influência do manejo florestal, toma especial importância para a manutenção do turismo e deste patrimônio natural.
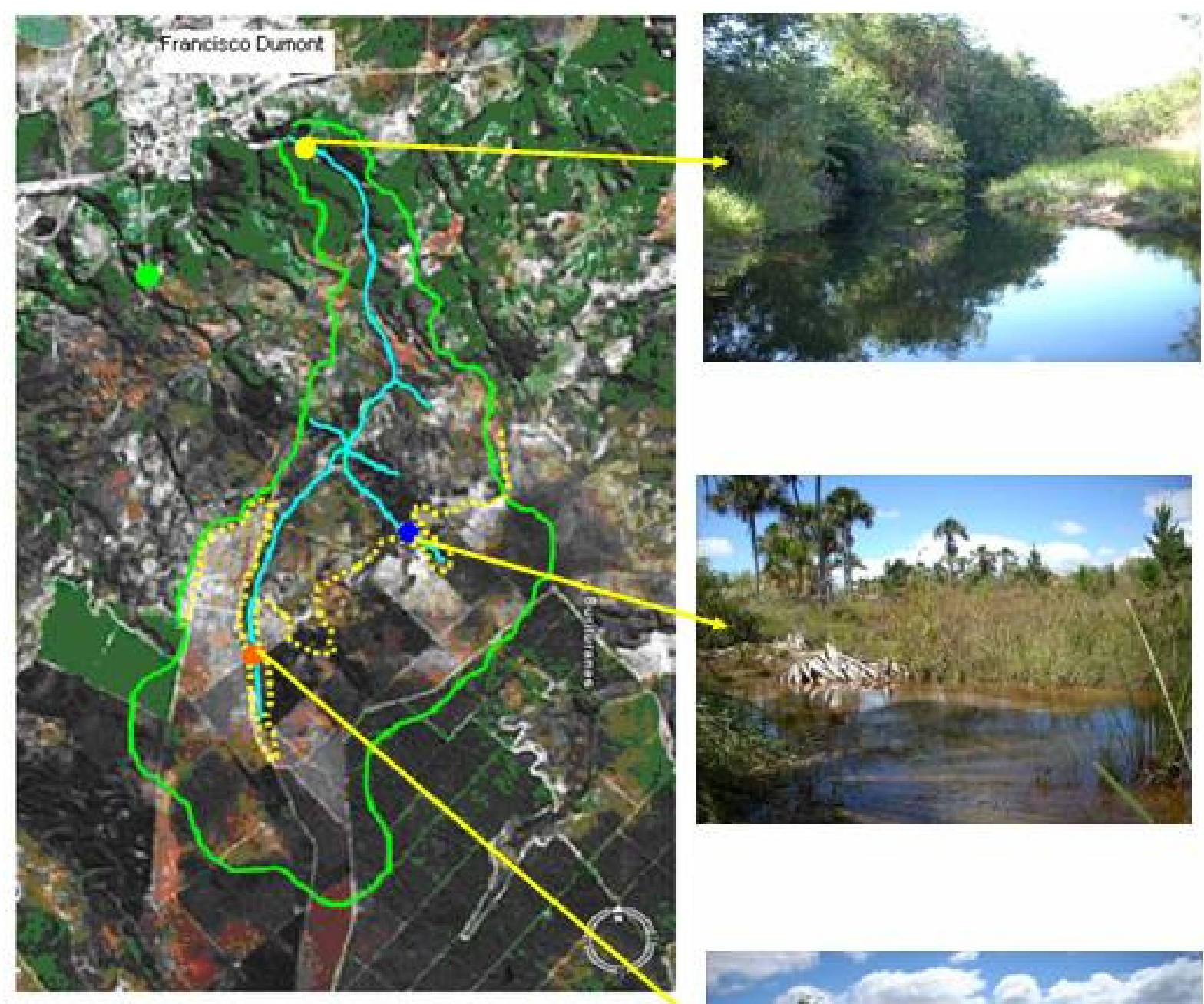

Legenda

\begin{tabular}{|l|l|}
\hline & Limites da Bacia Hidrográfica do Cómego Aguida \\
\hline & Curso principal e seus afluentes \\
\hline & Limites da Area de Protecăo Permanente \\
\hline & Ponto 1 de medicăo da vazäo: foz do córrego \\
\hline - & Ponto 2 de mediçăo da vazăo localiza do na vereda \\
\hline e & Ponto 3 de mediçäo da vazäo localiza do na vereda \\
\hline & Guanta da fazenda \\
\hline
\end{tabular}

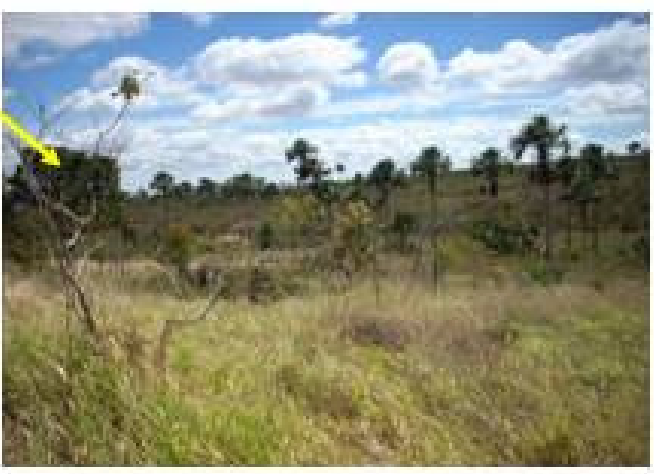

Figura 2: Imagem da microbacia hidrográfica do córrego Águida destacando os pontos de monitoramento da vazão e da vegetação no município de Francisco Dumont, MG. 


\subsection{Fluviometria e pluviometria}

Para quantificação das águas na bacia experimental foram realizadas medições contínuas de precipitação pluviométrica e da vazão. Este monitoramento iniciou no mês de setembro de 2007 abrangendo até os dias atuais.

O monitoramento vem sendo efetuado desde o início dos plantios de Eucalipto na microbacia em estudo, podendo ser mantido até a reforma dos plantios.

\subsubsection{Medição da precipitação}

No decorrer do período foram instalados oito pluviômetros e um pluviográfo, sendo que os pluviômetros foram confeccionados com diâmetro de abertura de $10 \mathrm{~cm}$. Estes foram instalados em locais estratégicos: um em cada nascente (num total de três), um na guarita, um no viveiro de espera, um na cascalheira e um no escritório de empresa. O pluviógrafo digital tem diâmetro de abertura de $20 \mathrm{~cm}$ e se encontra na guarita da fazenda (Figura 2).

As leituras são realizadas por funcionários da empresa a cada evento de chuva e registradas na planilha de dados. Para coleta da água das chuvas utilizam-se provetas de 500 $\mathrm{ml}$ e $1000 \mathrm{ml}$ para a medição do volume, que posteriormente é convertido em milímetros de chuva. Para determinar a precipitação mensal para área da bacia foram realizadas médias aritméticas dos dados dos pluviômetros e do pluviógrafo.

\subsubsection{Medição da vazão}

Para obtenção da vazão, foram realizadas visitas para a escolha dos pontos adequados, desta forma determinou-se três pontos, sendo o ponto um na foz da bacia, e os outros dois em veredas próximos às nascentes. Com estes dados obtêm-se a vazão total da microbacia e a contribuição das nascentes para a vazão total.

Para realizar as medições utilizou-se equipamento denominado micromolinete Flow Probe FP101(Figura 3), que mede a velocidade do fluxo de água em metros por segundo. Desta forma a vazão foi estimada através da área média da secção do córrego multiplicada pela velocidade do fluxo, como demonstrado na equação (1) a seguir:

$\mathrm{Q}=\mathrm{As} * \mathrm{~V}$ Equação (1)

Em que,

$\mathrm{Q}=$ vazão do córrego $\mathrm{em} \mathrm{m}^{3} / \mathrm{s}$,

As = área da seção em $\mathrm{m}^{2}$

$\mathrm{V}=$ velocidade $\mathrm{em} \mathrm{m} / \mathrm{s}$.

As medições são realizadas mensalmente durante três dias consecutivos. Em cada dia são realizadas 10 repetições de 2 minutos cada, gerando planilha como exemplificado abaixo. Para cada repetição de 2 minutos obtêm-se a vazão média em $\mathrm{m} / \mathrm{s}$, com as 10 repetições são calculadas as médias diárias. Finalmente é obtêm-se a média dos três dias de medição, que representa a velocidade $\mathrm{em} \mathrm{m} / \mathrm{s}$ do ponto mensal. 
Tabela 1: Metodologia de coleta de dados da vazão

\begin{tabular}{|c|c|c|c|c|c|c|c|c|}
\hline \multicolumn{3}{|c|}{ PONTO 1} & \multicolumn{3}{|c|}{ PONTO 2} & \multicolumn{3}{|c|}{ PONTO 3} \\
\hline $1^{\circ} \mathrm{Dia}$ & $2^{\circ} \mathrm{Dia}$ & $3^{\circ} \mathrm{Dia}$ & $1^{\circ} \mathrm{Dia}$ & $2^{\circ} \mathrm{Dia}$ & $3^{\circ} \mathrm{Dia}$ & $1^{\circ} \mathrm{Dia}$ & $2^{\circ} \mathrm{Dia}$ & $3^{\circ} \mathrm{Dia}$ \\
\hline Rep 1 & Rep 1 & Rep 1 & Rep 1 & Rep 1 & Rep 1 & Rep 1 & Rep 1 & Rep 1 \\
\hline Rep 2 & $\operatorname{Rep} 2$ & Rep 2 & Rep 2 & $\operatorname{Rep} 2$ & $\operatorname{Rep} 2$ & $\operatorname{Rep} 2$ & Rep 2 & Rep 2 \\
\hline Rep 3 & Rep 3 & Rep 3 & Rep 3 & Rep 3 & Rep 3 & Rep 3 & Rep 3 & Rep 3 \\
\hline$\ldots$ & $\ldots$ & $\ldots$ & $\ldots$ & $\ldots$ & $\ldots$ & $\ldots$ & $\ldots$ & $\ldots$ \\
\hline Rep 10 & Rep 10 & Rep 10 & Rep 10 & Rep 10 & Rep 10 & Rep 10 & Rep 10 & Rep 10 \\
\hline média 1-10 & média 1-10 & média 1-10 & média 1-10 & média 1-10 & média 1-10 & média 1-10 & média 1-10 & média 1-10 \\
\hline M. Ponto: & $\mathbf{m} / \mathbf{s}$ & & M. Ponto: & $\mathbf{m} / \mathbf{s}$ & & M. Ponto: & $\mathbf{m} / \mathbf{s}$ & \\
\hline
\end{tabular}

\subsubsection{1. Área média da secção}

Para o cálculo das áreas seccionais nos pontos de medição da vazão do córrego, medem-se as profundidades a 10 ou $20 \mathrm{~cm}$ de equidistância e a largura da seção do córrego. Para cada uma dessas secções em $\mathrm{m}^{2}$, é calculada a área de acordo com a figura abaixo.
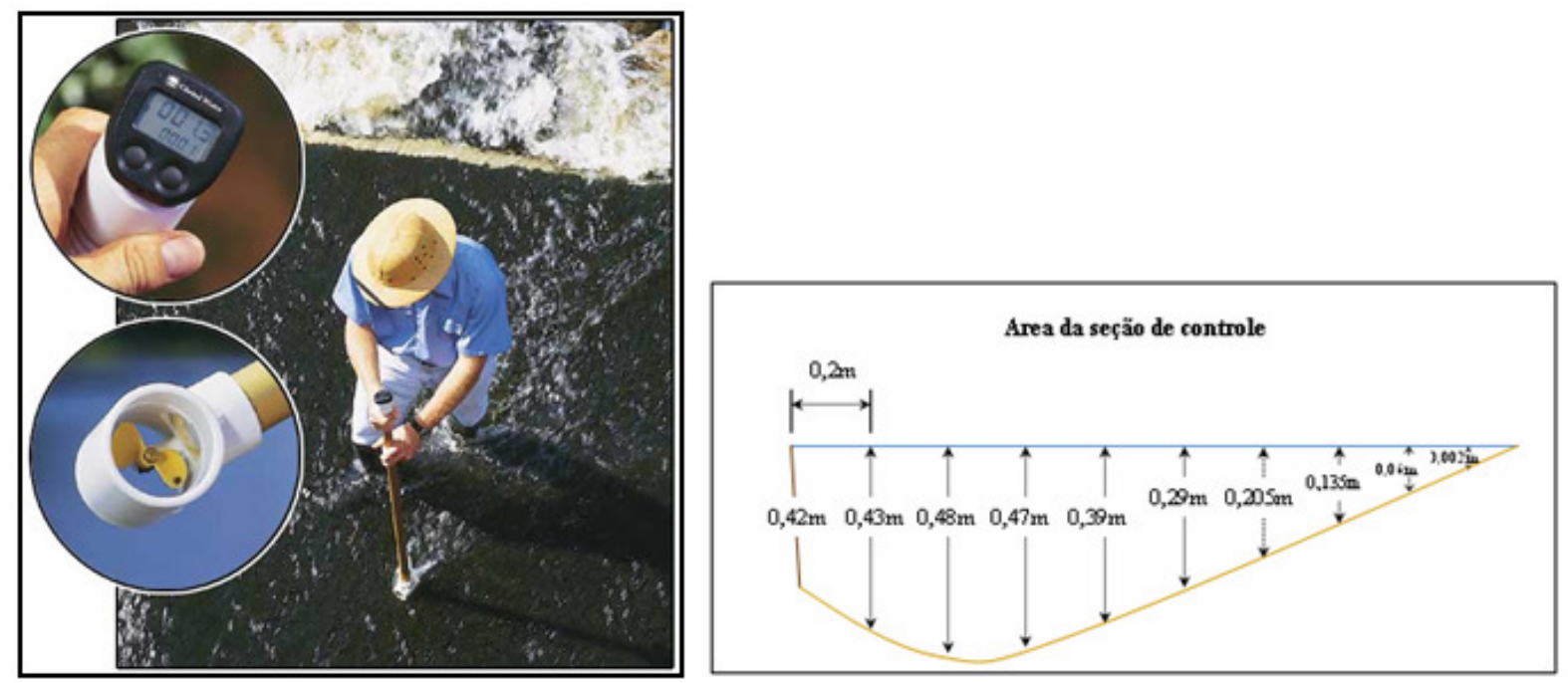

Figura 3: Micromolinete Flow Proble FP101 (a). Esquema representativo para cálculo da área da secção do córrego Águida, Francisco Dumont (b), MG.

\section{Resultados}

\subsection{Precipitação}

A precipitação na bacia foi de $863 \mathrm{~mm}$ em 2008, apresentando um longo período de estiagem (maio a agosto) com chuvas concentradas no período verão (setembro a abril), Tabela 2 e Figura 5. Em 2008 a precipitação no período de estiagem foi de 0,6 mm e a precipitação do período chuvoso de $862,4 \mathrm{~mm}$, demonstrando a forte concentração das chuvas na bacia.

Na Figura 6 observa-se a precipitação acumulada durante os meses de estudos. A inclinação do gráfico demonstra o volume de chuva, ou seja, quanto maior a inclinação maior é o volume de chuva nestes meses. Quando a linha da precipitação acumulada apresenta-se retilínea indica que não houve acréscimo de precipitação, ou seja, não houve chuva na bacia nos meses. 
Tabela 2: Precipitação mensal no período de Setembro de 2007 a Abril de 2009 na microbacia do Córrego Águida, Francisco Dumont, MG.

\begin{tabular}{|l|c|c|c|}
\hline \multicolumn{1}{|c|}{ Mês } & $\mathbf{2 0 0 7}$ & $\mathbf{2 0 0 8}$ & $\mathbf{2 0 0 9}$ \\
\hline Janeiro & - & 82,0 & 280,3 \\
\hline Fevereiro & - & 60,1 & 27,5 \\
\hline Março & - & 168,2 & 11,7 \\
\hline Abril & - & 59,5 & 17,8 \\
\hline Maio & - & 0,6 & 0,6 \\
\hline Junho & - & 0,0 & 0,0 \\
\hline Julho & - & 0,0 & 0,0 \\
\hline Agosto & - & 0,0 & \\
\hline Setembro & 75,0 & 10,0 & \\
\hline Outubro & 112,0 & 17,0 & \\
\hline Novembro & 55,6 & 220,0 & \\
\hline Dezembro & 128,2 & 245,6 & \\
\hline TOTAL & $\mathbf{2 9 5 , 8}$ & $\mathbf{8 6 3 , 0}$ & $\mathbf{4 3 7 , 9}$ \\
\hline
\end{tabular}

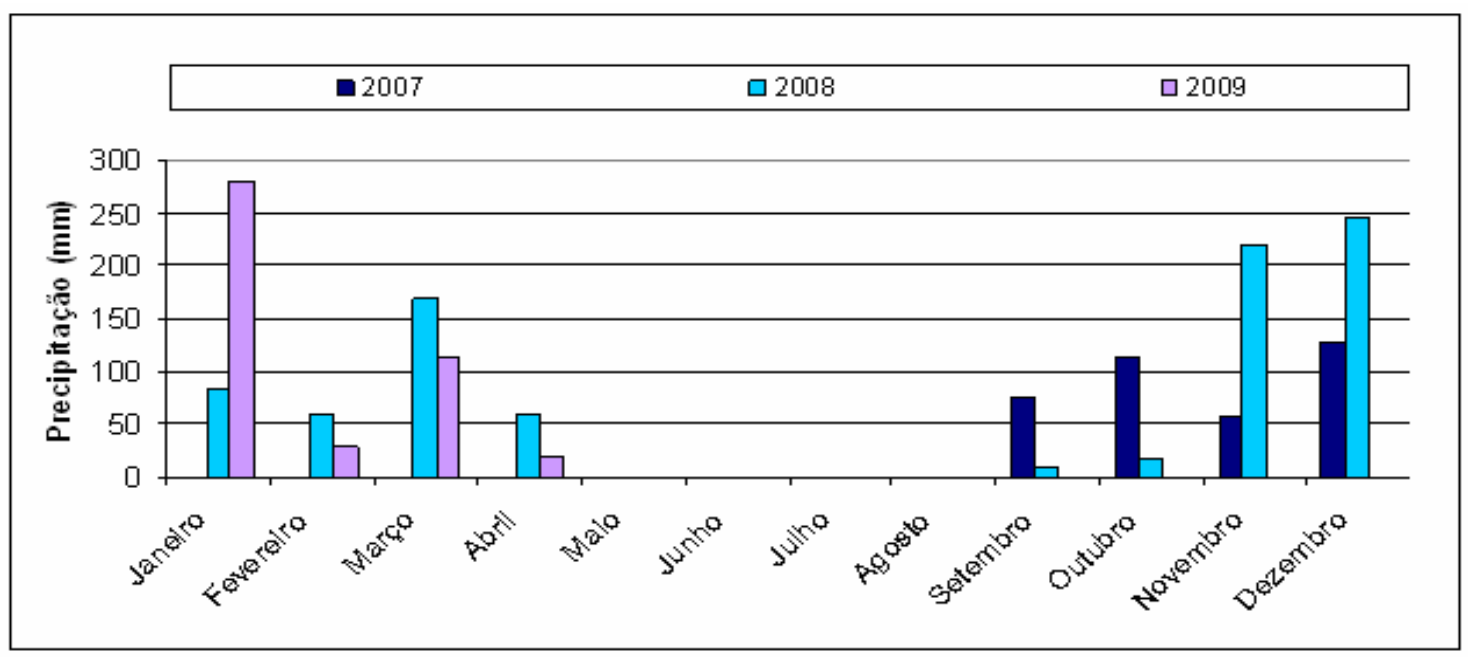

Figura 5: Distribuição temporal da precipitação na microbacia hidrográfica do córrego Águida em Francisco Dumont, MG.

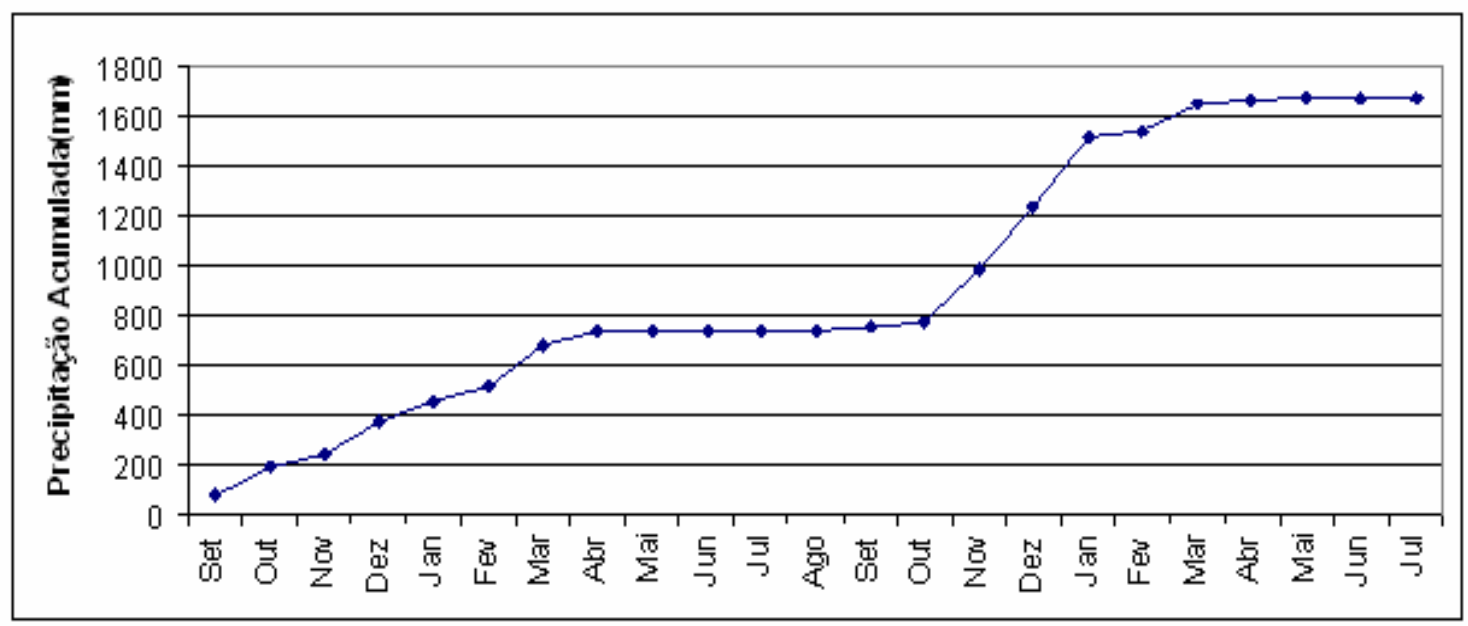

Figura 6: Precipitação acumulada na Bacia hidrográfica do Córrego Águida em Francisco Dumont, MG. 


\subsection{Vazão}

Os dados de vazão juntamente com as precipitações são apresentados na Figura 7. As vazões medidas podem indicar a resposta da microbacia em relação às precipitações e sua capacidade de armazenar água.

Ao se confrontar os dados de vazão e precipitação verificou-se uma relação direta entre eles. Em alguns momentos o aumento da vazão não acompanha o aumento da precipitação imediatamente, ou seja, o efeito das chuvas na vazão é retardado, como pode ser observado nos pontos 2 e 3 em ambientes de vereda. Já no ponto 1, localizado na foz da bacia, as chuvas causam um aumento instantâneo na vazão, efeito direto.

Observa-se ainda que nos meses de estiagem a vazão mínima nos pontos próximos as nascentes permanecem constantes o que provavelmente representa a capacidade de armazenamento de água do solo da bacia.

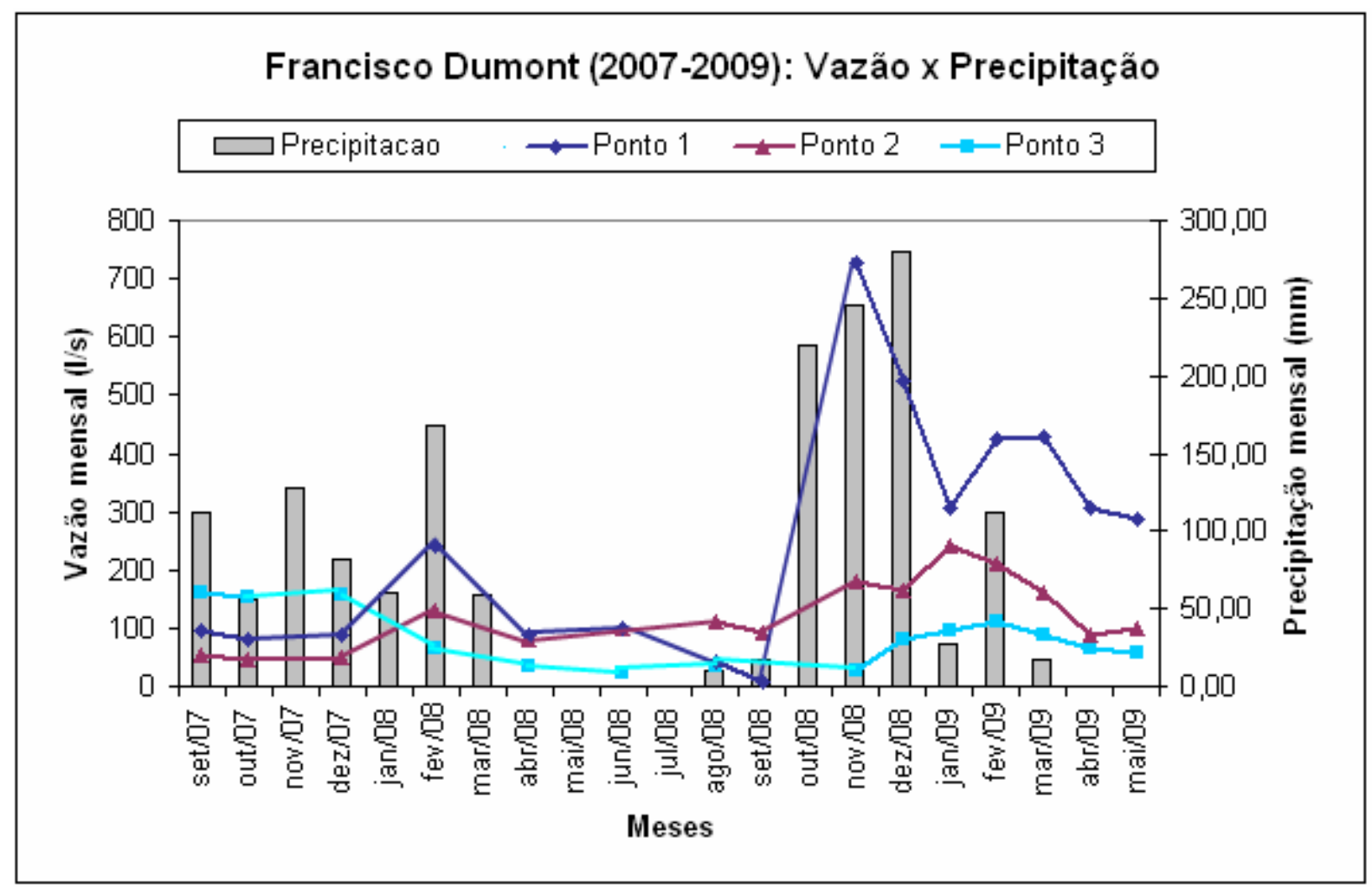

Figura 7: Precipitação e a vazão nos pontos medição: 1 - foz da bacia; 2 - Vereda 1, 3 -

Vereda 2, na microbacia hidrográfica do córrego Águida em Francisco Dumont, MG.

\section{Conclusão}

De acordo com as análises realizadas no trabalho pode-se concluir que:

- A precipitação no período avaliado apresenta-se bastante atípico do esperado tanto no total anual precipitado quanto na distribuição temporal.

- A vazão da microbacia, medida na foz, apresenta relação direta com a precipitação. 
- O Ponto três, mais distante da foz da bacia, apresenta um retardamento nas respostas à precipitação, e o ponto dois é o intermediário.

- A vazão mínima permanece constante durante todo o período de estiagem indicando a não interferência dos plantios de Eucalipto na área e um grande armazenamento de água no subsolo da microbacia.

\section{Agradecimento}

Os autores agradecem à Fundação de Apóio a Pesquisa do Estado de Minas Gerais, FAPEMIG, por financiar a participação no SERHIDRO.

\section{Referências}

ALVES, M.O. Caracterização e uso da bacia hidrográfica do Córrego Zerede, Timóteo, MG. Dissertação (Mestrado em Ciência Florestal) - Universidade Federal de Viçosa, Viçosa, MG, 2005.

CARDOSO, C.A; DIAS, H.C.T; MARTINS, S.V; SOARES, C.P.B. Caracterização hidroambiental da Bacia Hidrográfica do Rio Debossan, Nova Friburgo, RJ. Revista Árvore, Viçosa-MG, v.30, n.2, p.249-256, 2006.

DIAS, H.C.T; OLERIANO, E.S. A dinâmica da água em microbacias hidrográficas reflorestadas com eucalipto. In: I Seminário de Recursos Hídricos da Bacia Hidrográfica do Paraíba do Sul: o Eucalipto e o Ciclo Hidrológico, 09. 2007, Taubaté. Anais... Taubaté, SP: IPABHi 2007. Artigos p. 215-222.

JUNIOR, J.C.O. Precipitação efetiva em floresta estacional semidecidual na reserva Mata do Paraíso, Viçosa, MG. Dissertação (Mestrado em Ciência Florestal) - Universidade Federal de Viçosa, Viçosa, MG, 2006.

LIMA, W.P. Monitoramento de Bacias Hidrográficas em áreas florestadas. Série Técnica IPEF, Piracicaba, v.10, n.29, p.11 - 21, Nov.1996.

MOSCA, A.A.O. Caracterização hidrológica de duas microbacias visando a identificação de indicadores hidrológicos para o monitoramento ambiental para o manejo de floretas plantadas. Dissertação (Mestrado em Recursos Florestais) - Escola Superior de Agricultura Luiz de Queiroz, Universidade de São Paulo, SP, 2003.

OKI, V.K. Impactos da colheita de Pinus taeda sobre o balanço hídrico, a qualidade da água e a ciclagem de nutrientes em microbacias. Dissertação (Mestrado) - Escola Superior de Agricultura Luiz de Queiroz, Universidade de São Paulo, SP, 2002.

PINHEIRO, J.A.C. Processos hidrológicos na bacia hidrográfica do Córrego Zerede em Timóteo, MG. Dissertação (Mestrado em Ciência Florestal) - Universidade Federal de Viçosa, Viçosa, MG, 2008.

PRUSKI, F.F; PEREIRA, S.B; NOVAES, L.F; SILVA, D.D; RAMOS,M.M. Precipitação média anual e vazão média de longa duração, na Bacia do São Francisco. Revista Brasileira de Engenharia Agrícola e Ambiental, v.8, n.2/3, p.247-253, 2004, Campina Grande, PB, DEAg. 